\title{
Trace Contaminant Testing with the Orion Atmosphere Revitalization Technology
}

\author{
Amy B. Button ${ }^{1}$ \\ Engineering and Science Contract Group/Jacobs Technology, Houston, Texas, 77058 \\ Jeffrey J. Sweterlitsch ${ }^{2}$ \\ NASA Johnson Space Center, Houston, Texas, 77058 \\ and \\ Craig D. Broerman ${ }^{3}$ and Melissa L. Campbell ${ }^{4}$ \\ Engineering and Science Contract Group/Hamilton Sundstrand, Houston, Texas, 77058
}

\begin{abstract}
Every spacecraft atmosphere contains trace contaminants resulting from offgassing by cabin materials and human passengers. An amine-based carbon dioxide $\left(\mathrm{CO}_{2}\right)$ and water vapor sorbent in pressure-swing regenerable beds has been developed by Hamilton Sundstrand and baselined for the Orion Atmosphere Revitalization System (ARS). Part of the risk mitigation effort for this new technology is the study of how atmospheric trace contaminants will affect and be affected by the technology. One particular area of concern is ammonia, which, in addition to the normal spacecraft sources, can also be offgassed by the amine-based sorbent. In the spring of 2009, tests were performed at Johnson Space Center (JSC) with typical cabin atmosphere levels of five of the most common trace gases, most of which had not yet been tested with this technology. A subscale sample of the sorbent was exposed to each of the chemicals mixed into a stream of moist, $\mathrm{CO}_{2}$-laden air, and the $\mathrm{CO}_{2}$ adsorption capacity of the sorbent was compared before and after the exposure. After these typical-concentration chemicals were proven to have negligible effect on the subscale sample, tests proceeded on a full-scale test article in a sealed chamber with a suite of eleven contaminants. To isolate the effects of various test rig components, several extendedduration tests were run: without injection or scrubbing, with injection and without scrubbing, with injection of both contaminants and metabolic $\mathrm{CO}_{2}$ and water vapor loads and scrubbing by both the test article and dedicated trace contaminant filters, and with the same injections and scrubbing by only the test article. The high-level results of both the subscale and full-scale tests are examined in this paper.
\end{abstract}

\section{Nomenclature}

ARS = atmosphere revitalization system

ATCO = ambient temperature catalytic oxidizer

CAMRAS = Carbon dioxide And Moisture Removal Amine Swing-bed

CIS = Contaminant Injection System

$\mathrm{CO}=$ carbon monoxide

\footnotetext{
${ }^{1}$ Project Engineer, Exploration Life Support Atmosphere Revitalization Systems, 2224 Bay Area Boulevard, Mail Code JE77, AIAA Lifetime Member.

${ }^{2}$ Project Engineer, Exploration Life Support Atmosphere Revitalization Systems, 2101 Nasa Parkway, Mail Code EC3, not an AIAA Member.

${ }^{3}$ Project Engineer, Exploration Life Support Atmosphere Revitalization Systems, 2224 Bay Area Boulevard, Mail Code JE77, not an AIAA Member.

${ }^{4}$ Project Manager, Exploration Life Support Atmosphere Revitalization Systems, 2224 Bay Area Boulevard, Mail Code JE77, not an AIAA Member.
} 


$\begin{array}{ll}\mathrm{CO}_{2} & =\text { carbon dioxide } \\ \mathrm{CMS} & =\text { Contaminant Monitoring System } \\ \mathrm{GAC} & =\text { Gas Analyzer Console } \\ \mathrm{HMS} & =\text { Human Metabolic Simulator } \\ \mathrm{HSIR} & =\text { Human-Systems Integration Requirements } \\ J S C & =\text { Johnson Space Center } \\ \mathrm{kg} & =\text { kilograms } \\ \mathrm{lpm} & =\text { liters per minute } \\ \mathrm{mg} / \mathrm{d} & =\text { milligrams per day } \\ \mathrm{MSFC} & =\text { Marshall Space Flight Center } \\ \mathrm{NH} & =\text { ammonia } \\ \mathrm{NIST} & =\text { National Institute of Standards and Technology } \\ p p m & =\text { parts per million } \\ R T G A & =\text { Real Time Gas Analyzer } \\ S M A C & =\text { Spacecraft Maximum Allowable Concentration }\end{array}$

\section{Introduction}

In addition to $\mathrm{CO}_{2}$ and water vapor, humans give off a number of trace contaminant gases that can build up in a closed spacecraft atmosphere. Objects and surfaces used in the spacecraft cabin can also give off trace contaminant gases. Many of these trace contaminants can be harmful to humans at elevated concentrations. The Spacecraft Maximum Allowable Concentrations (SMAC) document ${ }^{1}$ details the permissible spacecraft concentrations of a great number of gas species over a range of exposure periods. The Constellation Program's Human-Systems Integration Requirements (HSIR) ${ }^{2}$ explicitly lists a subset of those gases and the exposure limits that must be regulated in the Orion vehicle, which are generally set at half of the 180-day SMAC levels. Orion's Atmosphere Revitalization System (ARS) would be responsible for removing excess contaminants from the cabin air; a conventional chemical filtration system combining packed beds of activated charcoal and ambient-temperature catalytic oxidizer (ATCO) is the primary contaminant control equipment in the design. A beneficial side effect of using a condensing heat exchanger to control humidity and temperature in a typical space vehicle's cabin is the capture of some trace gases, particularly ammonia $\left(\mathrm{NH}_{3}\right)$, in the condensate water. The Orion vehicle, however, was designed without a condensing heat exchanger, so the Orion ARS must take full responsibility for the trace contaminant control function.

Further complicating the ARS's trace contaminant gas control is Orion's core technology for $\mathrm{CO}_{2}$ and water vapor removal: a device the JSC test team calls the $\mathrm{CO}_{2}$ And Moisture Removal Amine Swing-bed, or CAMRAS. Hamilton Sundstrand has spent many years developing this amine-based, vacuum-regenerated sorption system as an alternative to traditional lithium hydroxide or zeolite-based $\mathrm{CO}_{2}$ sorption systems. The CAMRAS technology uses a pair of beds filled with SA9T, which is a sorbent system comprised of highly-porous plastic beads coated in an immobilized liquid amine compound, to remove $\mathrm{CO}_{2}$ and water vapor from a process gas stream. However, because the sorbent is an amine, it is known to generate small quantities of $\mathrm{NH}_{3}$ and it has the potential to interact with other trace contaminant gases.

Hamilton Sundstrand, the University of Hartford, Marshall Space Flight Center (MSFC), Kennedy Space Center, and other parties have performed subscale tests on the SA9T material in the past to examine its capacity for some individual contaminants. The remaining compounds from the HSIR list of trace contaminants were tested on subscale samples in spring 2009 at JSC. The principal objective of these tests was to verify that typical spacecraft trace contaminant levels would not cause detrimental effects to the full-size CAMRAS unit to be tested later in 2009 as part of the CAMRAS Phase 4A test series. In the full-scale tests, a mix of eleven contaminants was injected into the chamber while the ARS loop operated in various configurations, and the resulting atmospheric contaminant levels were monitored. For more information on the rest of the CAMRAS Phase 4A test series, see another paper from the first two authors at this conference.

\section{Subscale Tests}

SA9T interactions with toluene and pentane were tested in a laboratory at $\mathrm{JSC}^{3}$; these chemicals are on the SMAC list, but had not been previously investigated by other parties. Methanol, acetaldehyde, and formaldehyde interactions had previously been tested by Hamilton Sundstrand ${ }^{4}$, but they were included in the JSC test to examine the effects of typical vehicle concentrations instead of the high concentrations examined in Hamilton Sundstrand's 
tests. The aldehydes were shown by Hamilton Sundstrand to cause a slight degradation of SA9T's $\mathrm{CO}_{2}$ capacity, and the methanol seemed to have the potential to be controllable by the CAMRAS at lower concentrations.

\section{A. Subscale Test Rig Description}

For these JSC subscale tests, a test cell specifically designed to interface with a flow bench was packed with SA9T sorbent. $\mathrm{CO}_{2}$ and individual trace contaminants were metered into a humidified air stream that was passed through the test cell. The contaminant concentrations were equal to half of the 180-day SMAC level, which was designated as the nominal maximum level for the Orion atmosphere. The contaminant mixture flow rate was set to provide one-third of one second of residence time in the SA9T sample, also a reflection of the planned nominal Orion operations. A Diablo real-time gas analyzer (RTGA) used in conjunction with an Agilent mass spectrometer was first used to verify the trace contaminant load supplied to the test cell and then to monitor the gas stream exiting the test cell. Similarly, a California Analytical Instruments $\mathrm{CO}_{2}$ sensor was used to verify the $\mathrm{CO}_{2}$ load supplied to the test cell and then to monitor the gas stream exiting the test cell. The tested gas stream was then vented into a fume hood.

\section{B. Sample Conditioning and $\mathrm{CO}_{2}$ Capacity Baselining}

Hamilton Sundstrand, the SA9T manufacturer, stated that new SA9T needs to be conditioned by a few exposure and regeneration cycles before it will settle into a repeatable adsorption profile. To that end, as well as to establish the initial baseline $\mathrm{CO}_{2}$ adsorption capacity, each sample was first exposed to a humidified air and $\mathrm{CO}_{2}$ stream for 50 minutes and then vacuum desorbed for another 50 minutes, for a total of five adsorption and desorption cycles. The $\mathrm{CO}_{2}$ adsorption performance was typically very repeatable after the first cycle, and the 50 minutes was more than sufficient to saturate the SA9T's $\mathrm{CO}_{2}$ capacity; full $\mathrm{CO}_{2}$ breakthrough was typically observed after approximately 20 to 25 minutes. The conditioned samples were stored in individual sealed containers until the next tests.

\section{Trace Contaminant Breakthrough Tests}

Each of the samples conditioned and calibrated in the first portion of the test was next exposed to a single trace contaminant gas mixed with the humid, $\mathrm{CO}_{2}$-laden air stream. The contaminant mixture flow continued until breakthrough was observed, where breakthrough is defined as the point when the outlet concentration increases only very slowly and asymptotically. Table 1 summarizes the preliminary results of the trace contaminant breakthrough tests; further tests are planned.

Table 1. Subscale SA9T trace contaminant breakthrough test results.

\begin{tabular}{|l|c|c|c|c|}
\hline Contaminant & $\begin{array}{c}\text { Inlet } \\
\text { Contaminant } \\
\text { Concentration } \\
\text { (ppm) }\end{array}$ & $\begin{array}{c}\text { Breakthrough } \\
\text { Contaminant } \\
\text { Concentration } \\
\text { (ppm) }\end{array}$ & $\begin{array}{c}\text { Time to } \\
\text { Contaminant } \\
\text { Breakthrough } \\
\text { (min) }\end{array}$ & Comments \\
\hline Formaldehyde & 0.02 & 0.01 & 158 & \\
\hline Methanol & 3.5 & N/A & 307 & $\begin{array}{c}\text { stopped after 6 hours with } \\
\text { just over 25\% breakthrough }\end{array}$ \\
\hline Toluene & 2.0 & 1.1 & 56 & \\
\hline Pentane & 1.5 & 1.1 & 30 & N/A \\
\hline Acetaldehyde & 1.0 & 495 & $\begin{array}{c}\text { stopped after 8 hours with } \\
\text { just over 25\% breakthrough }\end{array}$ \\
\hline
\end{tabular}

\section{Postcontamination $\mathrm{CO}_{2}$ Capacity Tests}

To determine the lasting effects of exposure to these trace contaminants, if any, each sample was vacuum desorbed for as long as it had been exposed to the contaminant mixture flow. This desorption was performed immediately after the trace contaminant exposure test. Each sample was then subjected to five more cycles of adsorption of a humid air stream with $\mathrm{CO}_{2}$ with subsequent desorption, as in the baselining tests.

For the two aldehydes, $\mathrm{CO}_{2}$ adsorption capacity was slightly diminished for the first couple of cycles after the contaminant breakthrough test, suggesting that the identical desorption time as adsorption time was insufficient to fully remove all of the contaminant in the bed. For the remaining post-contamination cycles, however, the samples' $\mathrm{CO}_{2}$ capacities were essentially the same as the pre-contamination tests had demonstrated. Figure 1 illustrates this with the normalized $\mathrm{CO}_{2}$ breakthrough curves for the formaldehyde sample before and after the contamination test. 
There were no noticeable residual effects on the $\mathrm{CO}_{2}$ removal capacity of the SA9T samples for the other three contaminants.
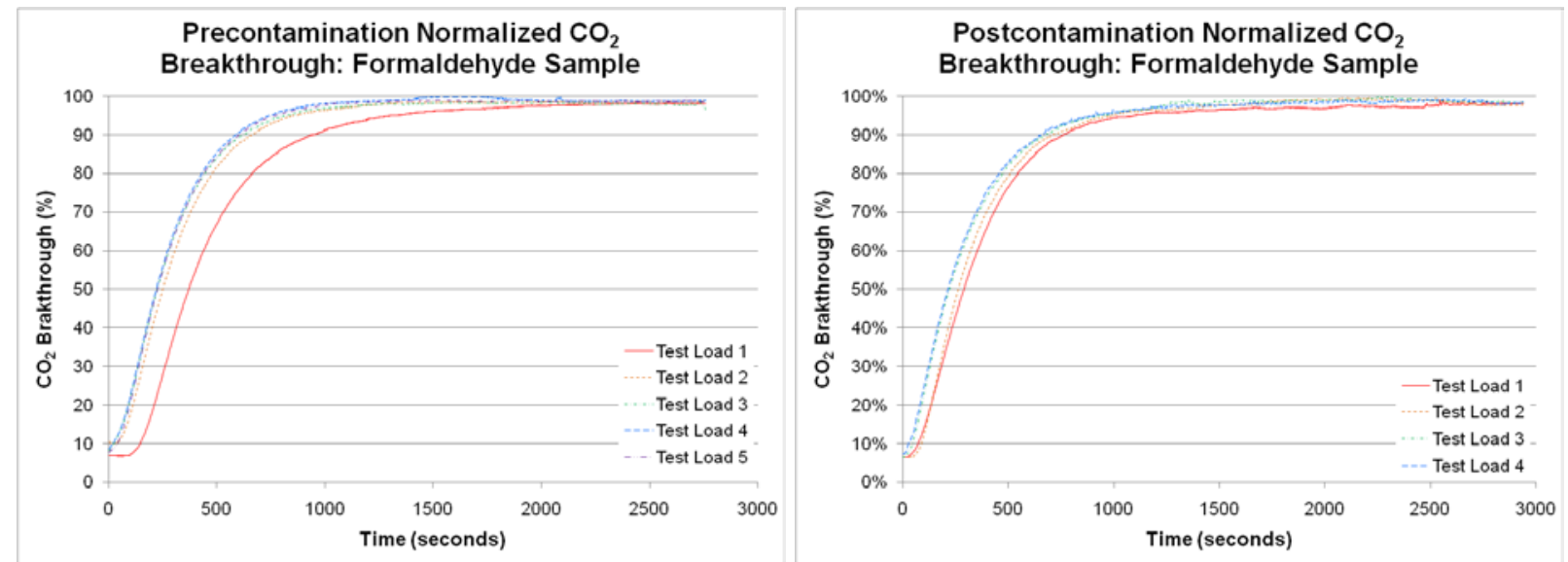

a) Precontamination.

b) Postcontamination.

Figure 1. Normalized $\mathrm{CO}_{2}$ breakthrough for SA9T sample with formaldehyde.

\section{Full-scale Test Rig Description}

After these subscale tests, in addition to the earlier tests by other parties had proven that the selected list of trace contaminants would not harm the full-scale CAMRAS test article, contaminant tests proceeded with CAMRAS unit 3 in the summer of 2009 as part of CAMRAS Phase 4A testing. The following paragraphs describe the Phase 4A trace contaminant testing rig.

\section{A. ARS Process Loop}

To evaluate the CAMRAS for Orion use, it was placed in a controllable, well-mixed atmosphere of the appropriate volume. A motive force for airflow through the amine beds and a vacuum source to simulate a link to space vacuum was provided, as was a supply of dry pressurized air representing a launchpad capability. The effects of humans on the cabin atmosphere were simulated with a Human Metabolic Simulator (HMS), and the whole test rig was outfitted with various sensors to monitor test conditions and experimental results. Figure 2 shows a simple diagram of the test rig described in this section. 


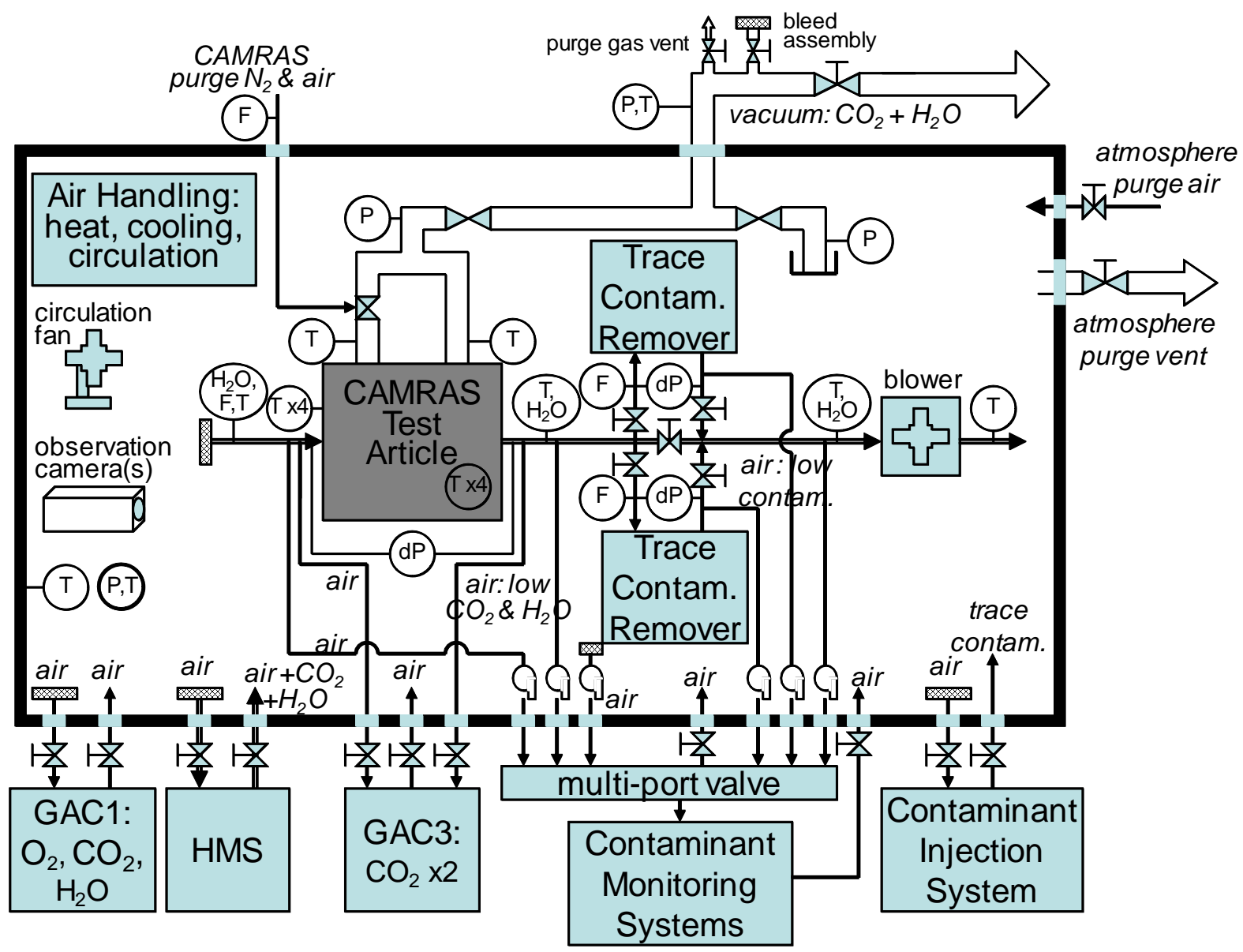

Figure 2. CAMRAS Phase 4A simplified test rig schematic.

Air flowed from the process loop inlet past a filter, flow meter, and several sensors before passing into the CAMRAS air inlet port on the top of the unit. Air flowed out of the CAMRAS unit through another line, where several more sensors were located. A set of valves could be reconfigured to route flow either through parallelplumbed trace contaminant filters, one packed with activated charcoal and the other packed with activated charcoal and ATCO, or through a line bypassing those filters, and then on to the blower. The blower outlet air was returned to the chamber atmosphere. External gas analyzer consoles (GACs) monitored sample gas streams from the chamber atmosphere and from the CAMRAS inlet and outlet lines, and all samples were returned to the chamber.

The test chamber volume was equivalent to half of the Orion free volume, as the normal vehicle operations would call for two operating CAMRAS units but only one was used for these tests. The HMS was designed to simulate human production of $\mathrm{CO}_{2}$ and exhaled $\mathrm{H}_{2} \mathrm{O}$ vapor. For the trace contaminant test cases in CAMRAS Phase 4A that included the use of the CAMRAS test article, $\mathrm{CO}_{2}$ was injected into the chamber atmosphere at $2.16 \mathrm{~g} / \mathrm{min}$, and water was injected as steam at $3.53 \mathrm{~g} / \mathrm{min}$. These rates represent half of the load of a crew of six. A six-person crew is no longer a standard operational plan for Orion, but this test series was already in progress when that change was decided, and a six-person load can provide worst-case reference data. The contaminant injection and monitoring systems are described in more detail in the next sections.

The two trace contaminant filter canisters were designed based on the proposed Orion ARS design as of May, 2008, and scaled to match the CAMRAS Phase 4A test rig with half the volume and only one CAMRAS unit. Although the test filter design replicated the proposed Orion contaminant removal capacity, air flow rate, and pressure drop, it did not replicate the Orion filter geometry. The test filters were designed so that their individual pressure drops would cause the nominal $740 \mathrm{lpm}$ process gas flow to split, flowing $720 \mathrm{lpm}$ through the phosphoric acid-treated charcoal canister and the remainder through the charcoal and ATCO canister. 


\section{B. Trace Contaminant Injection}

The Contaminant Injection System (CIS) was originally developed by TDA Research; the JSC team had acquired a duplicate system for other testing and then recently modified it to suit the purposes of the CAMRAS Phase 4A testing. The JSC CIS can be used to simultaneously inject contaminants from compressed gas cylinders, permeation ovens, and liquid syringe pumps into an air stream circulated from and back to the test chamber. More information on the CIS development is presented in another paper at this conference.

Eleven trace contaminant chemicals were injected into the chamber at the anticipated typical generation rates included in the HSIR; Table 2 lists the rates for those chemicals studied in CAMRAS Phase 4A tests. The ELS ARS Element Lead at MSFC, who is an expert on trace contaminant control systems, advised the JSC team on the most appropriate subset of the full HSIR contaminant list to test. The total rates in this Table 2 were halved to match the test rig's half metabolic load, half Orion volume, and single CAMRAS unit. The HSIR list also includes an assumed ammonia generation rate for the CAMRAS units, but because the Phase 4A tests included an actual CAMRAS unit, there was no need to use the CIS to simulate its ammonia generation.

Table 2. HSIR metabolic and offgassing trace contaminant generation rates.

\begin{tabular}{|l|c|c|c|c|}
\hline Contaminant & $\begin{array}{c}\text { Equipment } \\
\text { Offgassing } \\
\text { Generation Rate } \\
\text { (mg/d-kg) }\end{array}$ & $\begin{array}{c}\text { Human } \\
\text { Metabolic } \\
\text { Generation Rate } \\
\text { (mg/d-person) }\end{array}$ & $\begin{array}{c}\text { Total Generation Rate } \\
\text { (mg/d for 6 people \& } \\
\mathbf{4 , 0 0 0} \text { kg equipment) }\end{array}$ & $\begin{array}{c}\text { CAMRAS } \\
\text { Phase 4A } \\
\text { Injection } \\
\text { Source }\end{array}$ \\
\hline Acetaldehyde & $1.1 \times 10^{-4}$ & 0.6 & 4.04 & permeation tube \\
\hline Acetone & $3.6 \times 10^{-3}$ & 19 & 128 & permeation tube \\
\hline Ammonia & $8.5 \times 10^{-5}$ & 50 & 300 & compressed gas \\
\hline Benzene & $2.5 \times 10^{-5}$ & 2.2 & 13.3 & liquid \\
\hline Carbon Monoxide & $2 \times 10^{-3}$ & 18 & 116 & compressed gas \\
\hline Dichloromethane & $2.2 \times 10^{-3}$ & 0.09 & 9.34 & liquid \\
\hline Ethanol & $7.8 \times 10^{-3}+1000 \mathrm{mg} / \mathrm{d}$ & 4.3 & 1057 & liquid \\
\hline Formaldehyde & $4.4 \times 10^{-6}$ & 0.4 & 2.41 & permeation tube \\
\hline Furan & $1.8 \times 10^{-6}$ & 0.3 & 1.81 & compressed gas \\
\hline Toluene & $2 \times 10^{-3}$ & 0.6 & 11.6 & liquid \\
\hline Xylene & $3.7 \times 10^{-3}$ & 0.2 & 16.0 & liquid \\
\hline
\end{tabular}

\section{Trace Contaminant Monitoring}

Samples of the chamber atmosphere and process air were monitored for trace contaminant levels throughout the testing. Samples were pulled from all locations continuously to keep the sample in the lines as "fresh" as possible. An automatically-cycling multiport valve was used to direct the flow from one sample stream at a time to three gas analyzers, and all of the gas streams were returned directly to the chamber atmosphere via a common line. The three gas analyzers were: the same Diablo RTGA and Agilent mass spectrometer used in the subscale testing, a Servomex carbon monoxide (CO) analyzer used because $\mathrm{CO}$ has the same molecular weight as nitrogen, and a Picarro $\mathrm{NH}_{3}$ analyzer used because distinguishing $\mathrm{NH}_{3}$ from water vapor is difficult with traditional gas analyzers. This analyzer suite and its sampling system were collectively referred to as the Contaminant Monitoring System (CMS). The sample sequence drew from alternating locations upstream and downstream of the CAMRAS to maximize the data coverage during each CAMRAS half-cycle. The multiport valve changed position every 40 seconds, which was experimentally determined to be the minimum time necessary to achieve effectively stable $\mathrm{NH}_{3}$ readings at each sample location. This timing had the additional benefit of not hitting the same point in the 6.5-minute CAMRAS valve cycling period every time, which could provide a more robust picture of the CAMRAS's effect on the contaminant gases over the course of a typical half-cycle.

The $\mathrm{CO}$ and $\mathrm{NH}_{3}$ concentrations were output in directly usable formats, but the RTGA data had to be processed with calibration data after the test series was over. Complications were encountered with the operation of the CMS that caused periods of lost data; however, due to the long duration of the four test cases, the test team is confident that the overall data trends are reliable. Continuous $\mathrm{CO}_{2}$ monitoring was performed for the chamber atmosphere and process gas stream upstream and downstream of the CAMRAS by Rosemount $\mathrm{CO}_{2}$ analyzers in other gas sample analysis racks. Continuous moisture analysis was performed by Vaisala probe sensors at various locations in the process loop. 


\section{Full-scale Test Cases and Results}

Four distinct trace contaminant-related test cases were run in CAMRAS Phase 4A. The chamber was purged of trace contaminants by a flow of facility air and vented outside the building. The chamber door was left open at least overnight between test cases to help ensure similar starting conditions for each case. These tests and their preliminary results are summarized in this section.

\section{A. Background Environment Evaluation}

The first trace contaminant test case did not use any contaminant injection. Instead, it established baseline levels of all of the contaminant chemicals inherent to the test chamber environment. All blowers and external plumbing loops were running and open to ensure that the interior surfaces of all pipes were exposed to the background monitoring. The CAMRAS unit and the two filter units were the only exceptions to the background evaluation; those elements had jumper hoses taking their places so that they would not remove or add contaminants while establishing the baseline. Ideally, the expected results would be low steady levels of all of the target contaminants. However, the real chamber had a known leak rate of approximately 9\% per day, and it had the potential for slowly rising levels of some contaminants due to possible offgassing by items inside the chamber, such as tape adhesive. The test case was allowed to run for 3.3 days.

\section{B. Chamber Surface Passivation Test}

The chamber surface passivation test case was split into two distinct sections.

1. Active Passivation

During the active passivation portion of the test, contaminants were steadily injected into the chamber, but metabolic $\mathrm{CO}_{2}$ and water loads were not. All blowers and external plumbing loops were open and running to ensure that the interior surfaces of all pipes were exposed to the contaminants. The CAMRAS unit and the two filter units were the only exceptions to the passivation exposure; those elements had jumper hoses taking their places so that they would not remove or contribute to the injected contaminants. This portion of the passivation test was run for 3.9 days. Ideally, all of the contaminant concentrations would rise steadily. In reality, it was expected that different contaminants would have different affinities for the various surfaces in the chamber and the plumbing lines, and thus would accumulate at different rates. Some contaminants were being injected at such low rates that there was doubt that their low accumulation levels would even be detectable.

2. Passive Decay

During the passive decay portion of the test, the contaminant injection was simply stopped and the chamber ambient levels were allowed to decay through leakage and further surface passivation. The chamber door was not opened between the two sections of this test case, and all of the gas circulation loops remained open and running. This portion of the passivation test was run for 3.3 days. Ideal concentration decay due to chamber leakage would follow an exponential curve, and surface passivation might be expected to change the rate of that decay.

\section{CAMRAS, ATCO, and Charcoal Filtered Test}

The filtered test case represented a nominal Orion ARS loop configuration, with the CAMRAS operating to remove injected $\mathrm{CO}_{2}$ and water vapor, and the CAMRAS outlet flow split between the two parallel-plumbed contaminant filters that would ostensibly remove the injected trace contaminants. The ATCO filter would primarily scrub $\mathrm{CO}$ from the process air, while the charcoal filter was expected to remove $\mathrm{NH}_{3}$ and medium and high molecular weight organic chemicals (e.g., benzene and furan). It was known that the CAMRAS would likely scrub some of the formaldehyde and acetaldehyde, and that it might generate some $\mathrm{NH}_{3}$. The test case was run for 3.0 days.

\section{CAMRAS-only Testing}

The CAMRAS-only test case was run to better understand the effects of the CAMRAS itself on the trace contaminant load, and particularly the $\mathrm{NH}_{3}$ load. The two contaminant filter lines were bypassed, and as in the previous test case, the HMS added $\mathrm{CO}_{2}$ and water vapor to the chamber atmosphere and the CIS injected trace contaminants. The test case was run for 3.2 days, but sequential operator errors reduced the period of fully reliable data to approximately the last 1.3 days of the case.

\section{E. Posttest RTGA Data Processing}

During the CAMRAS Phase 4A tests, the RTGA was used to monitor the ion counts of nine ion masses corresponding to nine of the chemicals in the trace contaminant mix. However, to be usable data, the ion counts had 
to be converted into chemical concentrations through measurements of calibration-standard gases and mathematical correlation to normalized mass spectrometry standards.

After the test series was completed, the RTGA was used to evaluate the counts of the same nine ions for knownconcentration calibration samples of the same gases. Nonzero counts were observed for all nine species at all nine ion peaks, even though particular gas species should not fracture into ions of all of those molecular masses. These false positive values indicated instrument bias in the RTGA, so the bias numbers were subtracted from the ion counts of the calibration standard data. This debiased data was then divided by the concentration of the calibration gas, resulting in an "ion count per concentration" factor for all nine ion peaks for all nine gas species.

The National Institute of Standards and Technology (NIST) maintains a list of normalized (concentrationindependent) mass spectrometry data ${ }^{5}$ that presents the expected ion peak distribution for individual gas species. In order to compare the debiased RTGA data with the NIST standard data distributions, the NIST data was mathematically scaled to match the greatest debiased test data ion counts for each species. Finally, this scaled NIST data was used to convert the debiased test ion count data to test concentration data with matrix algebra. For a more thorough explanation of this data processing methodology, see Ref. 6.

\section{F. Overall Test Results}

Ammonia ended up being the most interesting compound in the trace contaminant portion of the CAMRAS Phase 4A testing. The slope of the chamber $\mathrm{NH}_{3}$ level increase in the CAMRAS-only test case was lower than in the passivation case (see Fig. 3), which seems to suggest that the CAMRAS was actually scrubbing $\mathrm{NH}_{3}$ from the chamber air. At the same time, however, the ammonia level and its rise rate at the outlet of the CAMRAS were slightly higher than those at the inlet, which seems to corroborate the past body of data showing that the aminebased SA9T sorbent generates some $\mathrm{NH}_{3}$. This apparent discrepancy might be explained by the CAMRAS removing some of the total chamber $\mathrm{NH}_{3}$ load - perhaps bound to water vapor molecules and vented to vacuum during regeneration - at a faster rate than its $\mathrm{NH}_{3}$ offgassing. This unexpected result has become a particular focus of follow-on subscale testing at JSC in early 2010. As of the writing of this paper, the preliminary results of that test corroborate the hypothesis by affirming that the SA9T does appear to remove slightly more ammonia from the process stream than it generates when operated cyclically with a process stream of humidified and $\mathrm{CO}_{2}$-laden air. Note that the actual concentration values in Fig. 3 are not necessarily useful data - the relative slopes are the important aspect of this plot. 


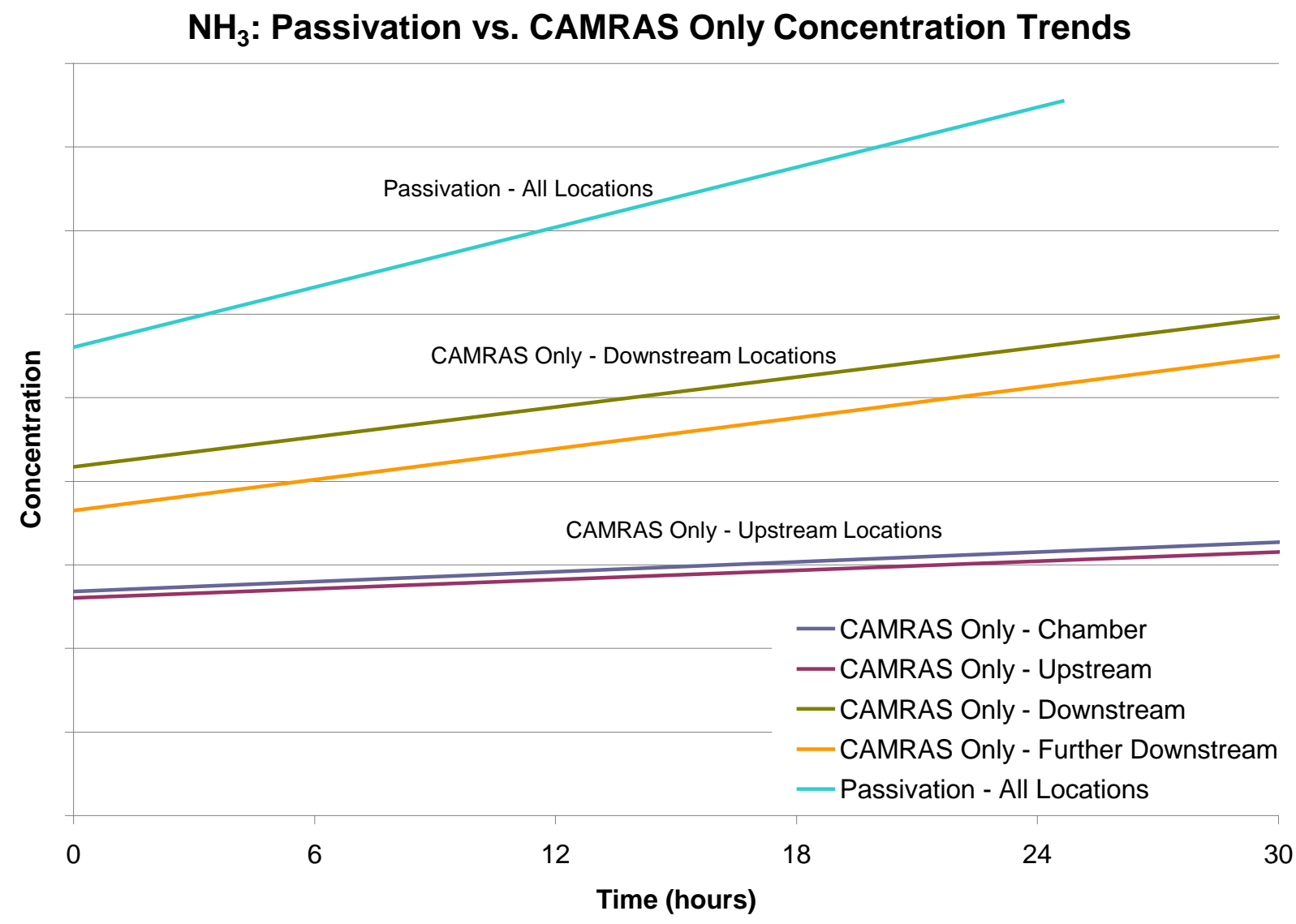

Figure 3. Ammonia concentration rise with no filtration versus with CAMRAS filtration.

The formaldehyde and acetaldehyde data are not considered reliable, as the concentration appeared to drop in all test cases, including the injection portion of the passivation case. This may simply be an issue with the calibration or mathematical processing; further investigation is warranted. However, both compounds appeared to specifically be removed by the CAMRAS; the downstream values were consistently far lower than the upstream values in both the filtered and CAMRAS-only cases.

Small rises were seen in the $\mathrm{CO}$ and $\mathrm{NH}_{3}$ levels over the course of the background test case. Ethanol and dichloromethane (also known as methylene chloride) appeared to rise somewhat at the beginning of the case and then alternately decrease and increase during the remainder of the case. The rest of the contaminants were all negligible at the beginning of the background test period and remained so throughout the case.

The ethanol and acetone data generally trended in the previously-described expected directions for each test case, but many of the calibrated concentration values ended up negative, despite the aspects of the mathematical processing intended to eliminate the negative values. Ethanol also appeared to be scrubbed by the CAMRAS. Carbon monoxide, dichloromethane, furan, and benzene behaved as expected through the series of tests. Toluene and xylene remained at effectively undetectable levels throughout all of the test cases, although both benzene and xylene had subtly lower readings downstream of the CAMRAS in both the CAMRAS-only and filtered cases. None of the compounds matched their ideally-expected concentration rise rates, which can most likely be attributed to leakage and surface passivation.

\section{Summary, Conclusions, and Future Work}

The JSC subscale SA9T testing was successful in verifying that none of the target trace contaminants at the maximum nominal levels allowed in the HSIR would irreversibly affect the $\mathrm{CO}_{2}$ performance of the full scale test article. This included formaldehyde and acetaldehyde, which had been previously shown to affect SA9T's $\mathrm{CO}_{2}$ adsorption capacity. Although the aldehydes did somewhat diminish the $\mathrm{CO}_{2}$ capacity in this test, it was reversible 
over a few uncontaminated adsorption and vacuum regeneration cycles. The SA9T was also newly shown to have little capacity for toluene or pentane.

The full scale CAMRAS trace contaminant tests are considered a partial success. The actual concentration data for most of the compounds are of questionable reliability and the levels accumulated during every test case were considerably lower than expected. Data sets from some of the individual contaminants make little sense for reasons such as consistently negative concentration values or concentration readings that decreased in every test case. However, the trends and relative concentrations for most of the contaminants are useful. Besides possibly ammonia and the known formaldehyde and acetaldehyde, ethanol, benzene, and xylene also appeared to be removed from the process stream by the CAMRAS to varying degrees. Other contaminants may have had slight removal by the CAMRAS, but the data was not of sufficient quality to clearly make that determination. The ammonia data suggest conclusions that counter assumptions based on earlier subscale testing in nonflightlike conditions. If verified by further, more rigorous, testing, this data could necessitate changes to the assumed CAMRAS ammonia generation rate included in the HSIR and could affect future technology trade decisions.

Further subscale trace contaminant testing of SA9T was conducted at JSC early in 2010, and other sorbents of interest are planned to be tested in the same manner. No further full scale trace contaminant tests are currently planned at JSC due to the complicated nature of the testing and data analysis, and also due to the relocation of the CAMRAS Phase $4 \mathrm{~B}$ test rig into a different chamber with different usage rules and other limiting factors.

\section{Acknowledgments}

The authors would like to acknowledge Tim Nalette, Bill Papale, and Bryan Murach of Hamilton Sundstrand for providing the test article and preliminary test data as well as technical support during the JSC tests and subsequent analysis insights. Jeff Sweterlitsch and Craig Broerman designed the subscale tests, and Craig Broerman and Matt Stubbe conducted them. For CAMRAS Phase 4A, JSC Test Facility Engineers Matt Blackmer, Peter Masi, Adrian Franco, and Jeremiah Nassif designed and directed the facility modifications, and Chamber Operator Technician Mitch Sweeney led the test rig buildup effort. Kevin Lange and Subra Sankaran sized the trace contaminant filter canisters, Richard McMahon and Mateo Chamberlain designed them under the project management of Melissa Campbell, and the canisters were manufactured by the JSC Materials and Processes Branch and packed by Matt Stubbe. The JSC ELS Air Revitalization team (Mary Walsh, Jeff Sweterlitsch, Melissa Campbell, Amy (Lin) Button, Su Curley, and Craig Broerman, plus technical consultants John Graf, Kevin Lange, Bruce Conger, and Rama kumar Allada) and ELS Air Revitalization Element Lead Jay Perry were instrumental in helping design the trace contaminant test points. Amy Button, Su Curley, and Matt Stubbe conducted the tests. NASA's ELS Program, Constellation Program, and Crew and Thermal Systems Division all helped fund the JSC CAMRAS testing program. This paper would not have been possible without all of their help.

\section{References}

1 James, J., "Spacecraft Maximum Allowable Concentrations for Airborne Contaminants," JSC-20584, Johnson Space Center, Houston, TX, 2008.

${ }^{2}$ National Aeronautics and Space Administration, "Constellation Program Human-Systems Integration Requirements, Rev. B, CxP 70024, 2008.

${ }^{3}$ Broerman, C., "SA9T Regeneration and $\mathrm{CO}_{2}$ Removal Evaluation Post Trace Gas Contamination Quick-Look Report," CTSD-ADV-720, Johnson Space Center, Houston, TX, 2009.

${ }^{4}$ Nalette, T., and Papale, W., "Final Report for Advanced $\mathrm{CO}_{2}$, Humidity, and Trace Contaminant Control System for Closed Loop Life Support Systems Project," Cooperative Agreement NNJ04HF73A, Hamilton Sundstrand Space Systems International, Inc., Windsor Locks, CT, 2008.

${ }^{5}$ NIST, NIST/EPA/NIH Mass Spectral Library with Search Program, Software Package, Data Ver. NIST 08, Software Ver. 2.0f, National Institute of Standards and Technology.

${ }^{6}$ Button, A., and Sweterlitsch, J., "CO 2 And Moisture Removal Amine Swing-bed (CAMRAS) Phase 4A Final Test Report," Johnson Space Center, Houston, TX, 2010 (to be published). 